\title{
Assessing the Impact of Climate Conditions on Harnessing Coastal (Offshore) Wind Energy
}

\author{
Shamima Akter ${ }^{1}$, Joon Kiat Loo $^{2}$ and Mohammed Abdul Hannan ${ }^{2}$ \\ ${ }^{1}$ Design and Planning, Khulna Shipyard Limited, Khulna, Bangladesh \\ ${ }^{2}$ Faculty of Science, Agriculture \& Engineering, Newcastle University, UK (Singapore Unit), \\ Singapore.
}

\begin{abstract}
This study analyses the relationship among various climate factors and their effect on the wind power density available in a coastal region. Climate data from several offshore wind farms in the East Asian region is extracted to perform the calculations and analysis. Reasons for variations of climate parameters such as average wind speed, average temperature, air density, average pressure, average precipitation, average humidity and their influences on wind power generation are explored. It is expected that this study will help the investors to perform a feasibility study on the availability of wind energy at a certain nearshore area before setting up wind farms.
\end{abstract}

\section{Introduction}

The world demand for energy results in the great usage of fossil fuels and nuclear energy. In the year 2016, fossil fuels (oil, coal, natural gas), nuclear energy and hydroelectricity contributed around $85 \%, 5 \%$ and $7 \%$ respectively to the world energy supply [1]. Rest of the $3 \%$ comes from the renewable energy. This large consumption of fossil fuels is significantly contributing towards global warming and it is predicted that by the end of this century, the likely range of global temperature increase is 2 to 4.9 degree Celsius [2]. Even if humans suddenly stopped burning fossil fuels now, Earth will continue to heat up about two more degrees by 2100 [3]. A faster transition towards renewable energy therefore, is of prime importance to fight this global problem. Among various alternatives, wind energy is one of the most reliable sources of renewable energy. Harnessing wind energy at onshore has become quite matured while development of offshore/coastal wind farms is still under research. Although offshore wind farms may cost more in terms of construction, maintenance and technology, as compared to onshore wind farms, it provides several distinct advantages as well. It is very difficult to find land in the densely populated coastal area to place onshore wind farms whereas space constraint is not a problem in the offshore area. Furthermore, offshore wind speed is usually higher and more consistent compared to onshore wind, thus providing an opportunity of producing more electricity.

${ }^{*}$ Corresponding author: sonalirajkonna@gmail.com 
However, various climate factors such as wind speed, wind direction, temperature, humidity, air density, air pressure and precipitation could easily affect the harnessing of offshore energy and importance of analysing such parameters are being highlighted in various research $[4,5]$. Power generated by offshore wind farms at various locations differ significantly, even if the offshore turbines may have the same dimension and capacity factor, as different countries have different climate conditions.

The objective of this study, therefore, is to evaluate and analyse the impact of climate variations on harnessing offshore wind energy. Existing researches focus on calculating the amount of electricity that can be produced by a certain wind turbine(s) for a particular wind speed in a location [6,7]. Instead of considering such approach i.e. focusing on how much power can be produced by the wind turbines, here influences of various climate factors on the generation of wind power will be discussed and wind energy will be reported in terms of per square meter. Such approach will help the investors and developers to have a better understanding on the availability of wind power at different climate conditions and to take their decision on the development of the wind farm (number, dimension and capacity of turbines, etc).

\section{Methodology}

\subsection{Collection of data}

In this study, five offshore wind farms have been selected from different countries and offshore regions within East Asia. They are Donghai Bridge Offshore wind farm (DBO), South-Taipower Offshore wind farm (STO), Maritime Offshore wind farm (MO), Incheon Offshore wind farm (IO) and Kamisu Offshore wind farm (KO). The detail of each wind farm (locations, capacity etc) can be found in table 1 .

Table 1. Locations of five coastal wind farms.

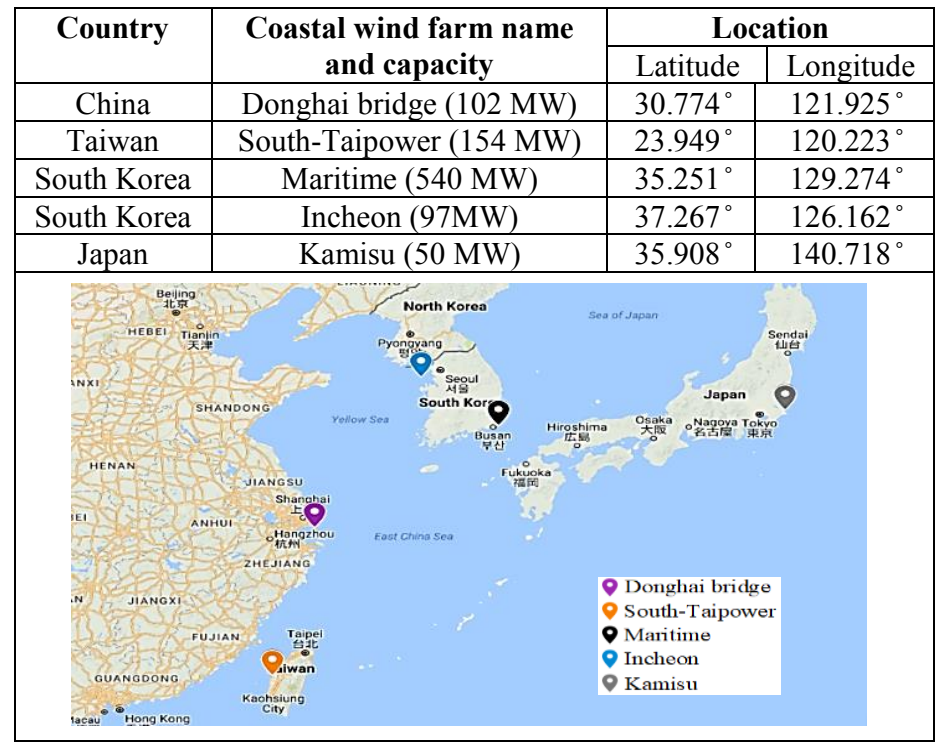

One year, 8 years and 30 years weather data will be used to calculate wind power density in these locations. Year 2016 and past 8 years (2009-2016) climate data are taken from World Weather Online [8], while past 30 years (1987-2016) climate data are taken 
from Meteoblue [9]. Reliability and accuracy for both sources are well assured and more information on this can be found in their websites.

\subsection{Wind power density}

Wind turbine power output can be calculated using the following equation:

$$
P_{T}=\frac{1}{2} \rho A v^{3} C p
$$

where $P_{T}$ is the wind turbine output in $W ; A$ is the rotor swept area in $m^{2} ; \rho$ is the air density in $\mathrm{kg} / \mathrm{m}^{3}, v$ is the average wind speed in $\mathrm{m} / \mathrm{s}$ and $C_{P}$ is the power coefficient of a wind turbine. It refers to the ratio of power able to extract by the turbine to the total power contained in the wind resource. Theoretically, 16/27 (59.3\%) is the maximum efficiency a wind turbine can hit, known as the Betz Limit [10]. However, practically, less than 16/27 (59.3\%) energy can be harness from wind, $75-80 \%$ of the Betz Limit will be the maximum. This theory is known as Betz's law.

However, in this paper, as wind turbine will not be considered in the calculation, rotor swept area and power coefficient will be taken out from the equation, thus forming the wind power density equation. Wind power density measures how much power per unit area is available in wind for harnessing and can be calculated using the following equation:

$$
P=\frac{1}{2} \rho v^{3}
$$

where $P$ is the wind power density in $\mathrm{W} / \mathrm{m}^{2}$

As for air density, it is proportional to the average air pressure, $p$ in $P a$ and inversely proportional to the product of both air temperature, $T$ in $K$ and gas constant for dry air in $J /$ $\mathrm{kg} \cdot \mathrm{K})$

$$
\rho=\frac{p}{R_{0} T}
$$

As mentioned above, climate parameters like average wind speed, average temperature and average air pressure will be extract from World Weather Online and Meteoblue for all five offshore wind farms under study. The data is then compared over a range of one year, 8 years and 30 years. For one year and 30 years' period, wind power density is calculated on monthly basis while for 8 years' period, it is calculated on annual basis instead. For 30 years period, both average air pressure and average humidity are not found and humidity data is only available for the year 2016 .

\section{Results and discussion}

Graphs for variations of average wind speed, average temperature, air density, average pressure, average precipitation, average humidity and wind power density are shown below. Impact of these climate parameters on wind power density is discussed. Wind rose diagrams are also shown at the end of this section to highlight the distribution of wind speed and direction, which also affects the harnessing of wind energy.

\subsection{Impact of wind speed variation}

The variations of monthly mean wind speed data for the year 2016 and 30 years' period for the five offshore wind farms are plotted in Fig 1(a) and Fig 1(b). Donghai bridge offshore wind farm, located at Shanghai, which is the centre of China's east coast; the highest wind 
speed of $7.5 \mathrm{~m} / \mathrm{s}$ occurs in October 2016 and highest average of $5.4 \mathrm{~m} / \mathrm{s}$ occurs in January and December for the last 30 years. Maritime offshore wind farm, located at Busan, Southeastern tip of Korea peninsula at Korea Strait; the highest wind speed of $4.6 \mathrm{~m} / \mathrm{s}$ occurs in February 2016 and highest average of $4.5 \mathrm{~m} / \mathrm{s}$ in January for last 30 years. Incheon offshore wind farm, located at Gyeonggi, Incheon, western coast of Korean Peninsula at Yellow Sea; the highest wind speed of $8 \mathrm{~m} / \mathrm{s}$ occurs in November 2016 and highest average of 4 $\mathrm{m} / \mathrm{s}$ in January for last 30 years. Kamisu offshore wind farm, located at Kamisu, extreme south-eastern of Ibaraki Prefecture, Kashima Nada Sea; the highest wind speed of $6.1 \mathrm{~m} / \mathrm{s}$ occurs in March 2016 and $7 \mathrm{~m} / \mathrm{s}$ in February for last 30 years. South-Taipower offshore wind farm, located at Changhua, Taiwan Strait Sea, the highest wind speed of $9.8 \mathrm{~m} / \mathrm{s}$ occurs in February and December 2016, and highest average of $3.6 \mathrm{~m} / \mathrm{s}$ in October and December for last 30 years.
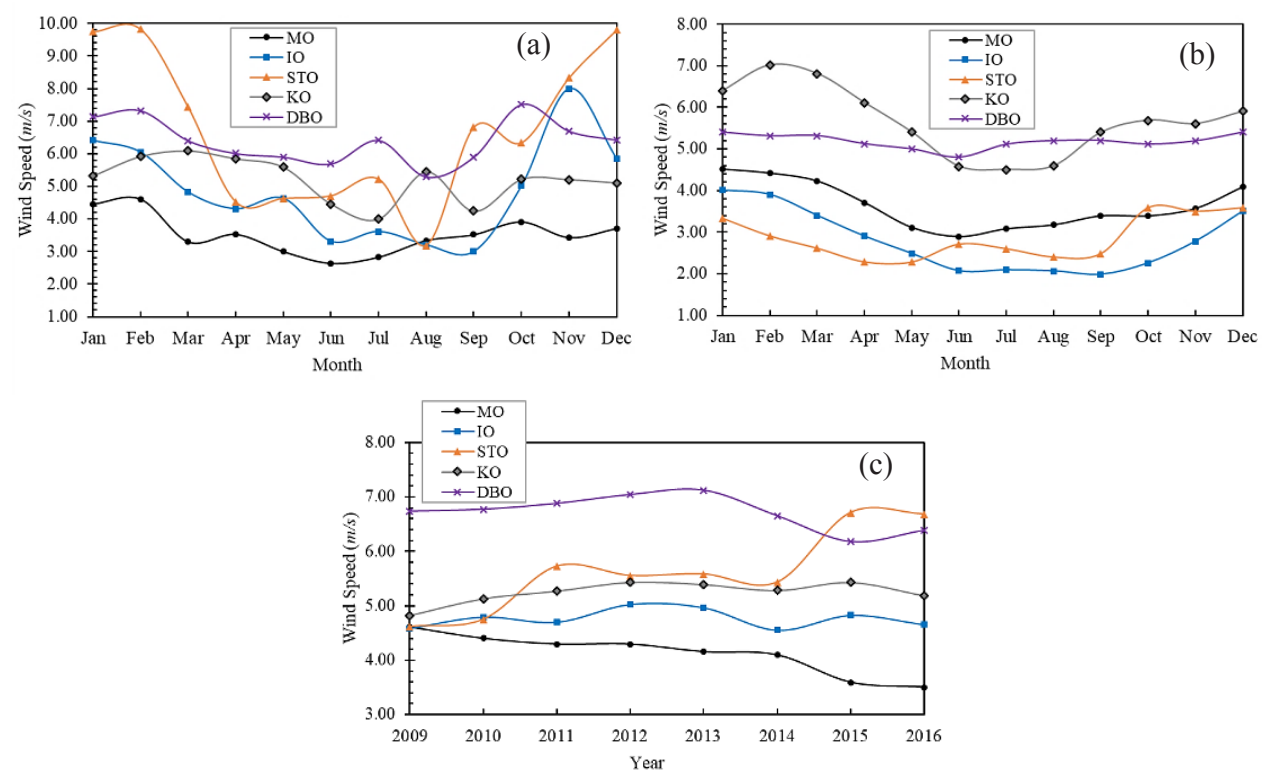

Fig. 1. Variations of average wind speed: (a) Monthly variation for the year 2016; (b) Monthly variation over the last 30 years; (c) Annual variation over 8 years.

Wind speed plays the most essential role in harnessing offshore wind energy, as power generated by wind is approximately proportional to the cube of wind velocity. This can be easily understood by comparing Fig 1(a) with Fig 7(a) and Fig 1(b) with Fig 7(b). Both of these pairs of the graph shows similar trends for all the five offshore wind farms under consideration. The final figure of this section, Fig 1(c) shows the annual variations of average wind speed to observe how the yearly wind speed varies over the last 8 years. As can be seen, an increasing/decreasing/periodic trend of wind speed variation can be observed from this graph. Besides, in Fig 1(a) and Fig 1(b), except few exceptions, most of the monthly variations in the year 2016 follows the 30 years' monthly variation patterns. These types of analyses will help the investors to obtain a preliminary estimation of the amount of wind energy expected to be harnessed throughout the year at any particular location before an investment decision is to be made. 


\subsection{Influence of temperature change}

Fig 2(a) and Fig 2(b) shows the monthly variations of average temperature for the five offshore wind farms throughout the year 2016 and over last 30 years' respectively. The temperature trends for both figures are very similar, except a slight increase in average monthly temperature in the year 2016 compared to the 30 years' average. This can be confirmed from Fig 2(c) as well, which depicts the variation of annual average temperature over the period of last eight years. As can be seen, the average temperature is mostly increasing gradually over the years. This certainly reflects the influence of global warming.
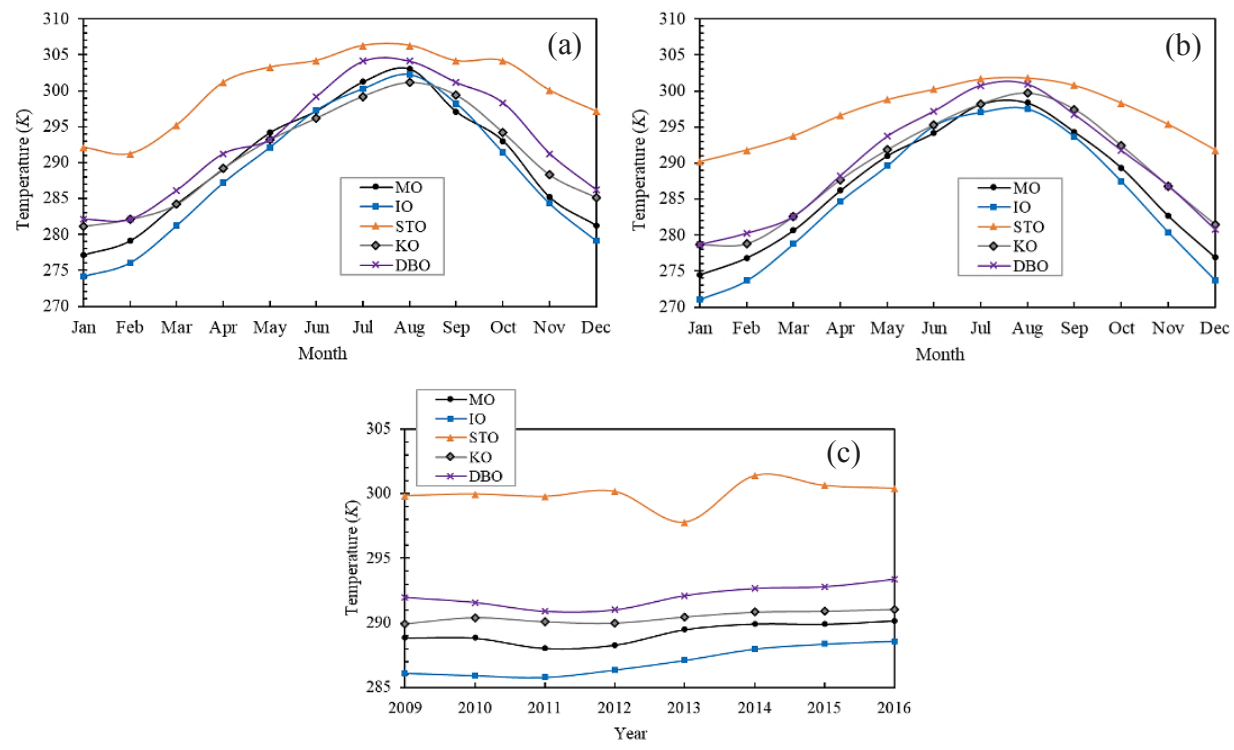

Fig. 2. Variations of average temperature: (a) Monthly variation throughout the year 2016; (b) Monthly variation over the last 30 years; (c) Annual variation over 8 years.

All the five wind farms are located within the East Asian region, therefore, exhibiting similar types of temperature pattern i.e. higher temperature in the $3^{\text {rd }}$ quarter of the year and a gradual decrease on other quarters, resulting in the lowest temperature near the December and January. South-Taipower offshore wind farm has a generally warm and temperate climate as it is located nearer to the Equator among all these five locations. Its average temperature throughout the year is therefore, higher than the other four offshore wind farms.

Now, the influence of temperature variation on wind power generation can be easily seen by comparing Fig 2(a) and 2(b) with Fig 7(a) and 7(b) respectively. As observed, wind power density shows a general increasing pattern with the decrease of temperature and vice versa. Although, the change is not as obvious as wind speed, however, it still produces significant effects on wind power. For example, at 'Kamisu Offshore', October and November in the year 2016 have the same wind speed of $5.2 \mathrm{~m} / \mathrm{s}$, but the temperature was $294.15 \mathrm{~K}$ and $288.15 \mathrm{~K}$ respectively; resulting in a wind power density of $84.76 \mathrm{~W} / \mathrm{m}^{2}$ in October and $86.61 \mathrm{~W} / \mathrm{m}^{2}$ in November. Thus, showing the influence of cooler average temperature on the increase of wind energy generation. 


\subsection{Effect of air density}

Air density is inversely proportional to temperature. As a result, air will be much denser in colder temperature compared to warmer temperature. This obvious relationship can be seen by comparing the respective plots in Fig 2 and Fig 3. Out of the five offshore wind farms, Incheon Offshore wind farm has the highest air density over the years. A comparison between the trend of air density variation and wind power generation (similar to the comparison mentioned in the earlier two sub-sections) reveals that the amount of kinetic energy in the wind depends on the air density, the denser the air, the higher the wind power density. A closer look to Fig 3(a) and Fig 7(a), and to Fig 3(b) and Fig 7(b) show that air density decreases until August and then started to increase till December and the wind power density also follow the similar patterns.
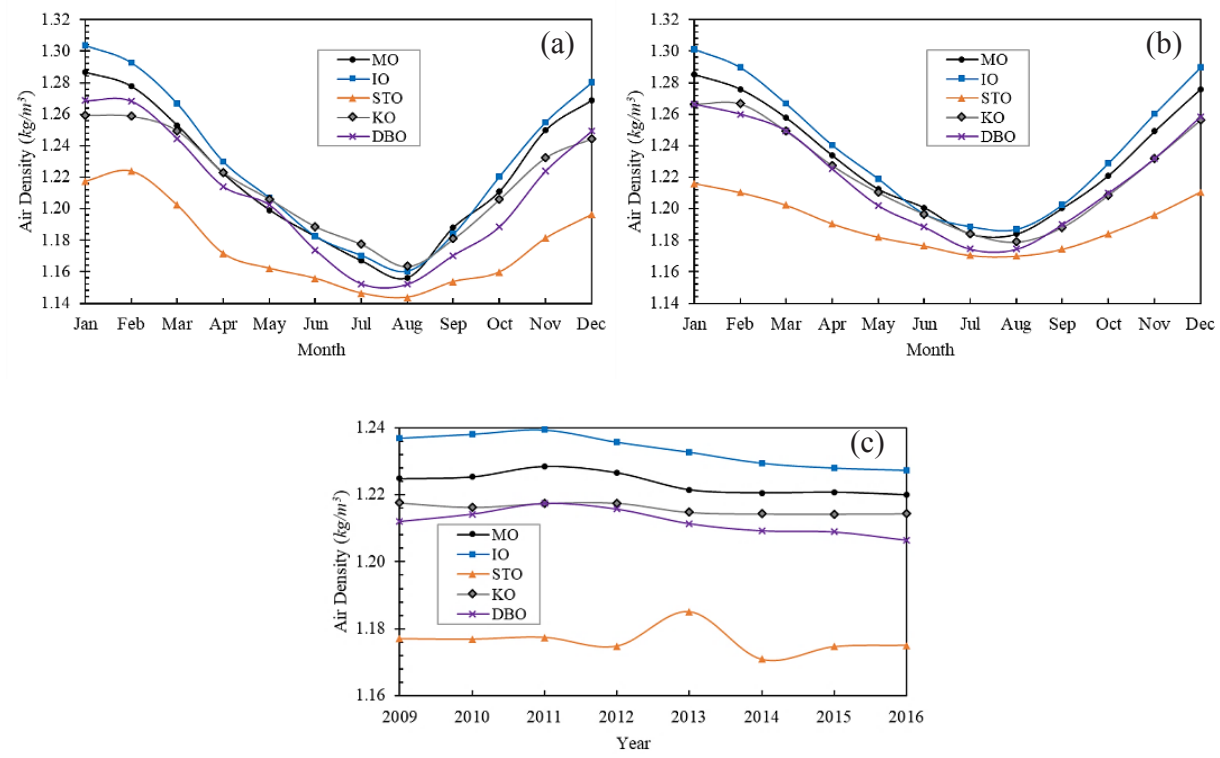

Fig. 3. Variations of air density: (a) Monthly variation throughout the year 2016; (b) Monthly variation over the last 30 years; (c) Annual variation over 8 years.

\subsection{Average atmospheric pressure variation}

As already mentioned in section 2, average air pressure data for the past 30 years were not found, therefore, only the monthly variation of air pressure over the year 2016 and the annual variations of average pressure over the last 8 years are depicted in Fig 4(a) and Fig 4(b) respectively. 

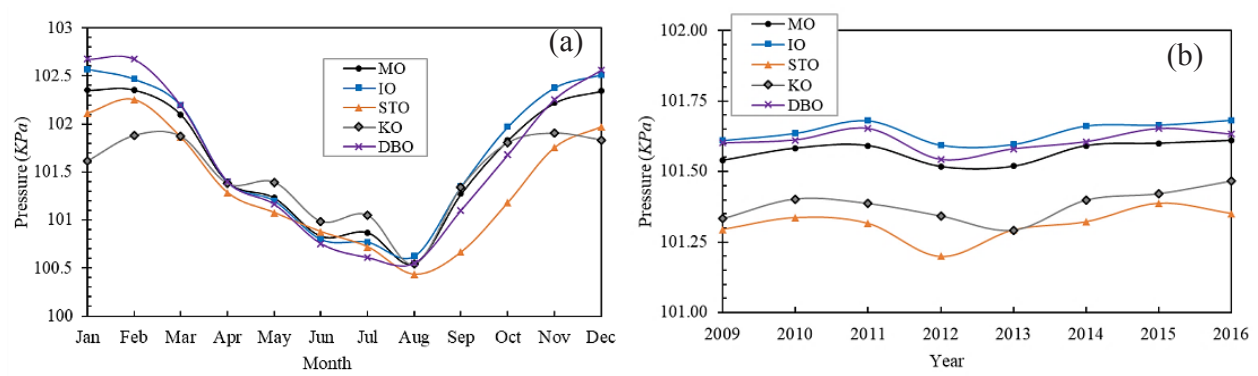

Fig. 4. Variations of average atmospheric pressure: (a) Monthly variation throughout the year 2016;

(b) Annual variation over 8 years.

Out of the five offshore wind farms, Incheon offshore wind farm has the highest average pressure over the years. As air pressure is the force exerted by the air, the more air molecules in the air, the greater the pressure will be. As a result, it is affected by the variation of temperature, air density and humidity. If the temperature decreases, air will be denser and an increase in air molecules will result in higher pressure. On the other hand, an increase in humidity means a higher percentage of water molecules in the air than gas molecules, thus, leading towards lower pressure. These relationships can be easily understood by comparing Fig 4(a) with Fig 2(a), Fig 3(a) and Fig 6. It can also be concluded that higher average pressure can result in higher wind power density, as observed during the comparison between Fig 4(a) and Fig 7(a).

\subsection{Influence of average precipitation}

As shown in Fig 5(a) and Fig 5(b), unlike the variation of temperature and air density (as reported in the previous two subsections), the trend of monthly average precipitation for the year 2016 is not following the same distinctive patterns with the monthly average of last 30 years. This might be attributed to the recent climate change. As noticed in Fig 5(b), for Shanghai, where Donghai Bridge offshore wind farm is located, rainy season is from April to September, thus there is quite a significant amount of rainfall during that period compared to other months. For Maritime Offshore at Busan, the summer season is hot, muggy and rainy; thus there is abundant rainfall from June to September. Gyeonggi, Incheon, west of Korean Peninsula is affected by East Asian Monsoon, experiencing a continental climate. As rain is very common in mid-summer, the precipitation amount is quite high from the end of May to early September there. In all these five locations, the rainfall is minimum from the end of November to early March due to the dry weather in winter, which are shown in both Fig 5(a) and Fig 5(b).
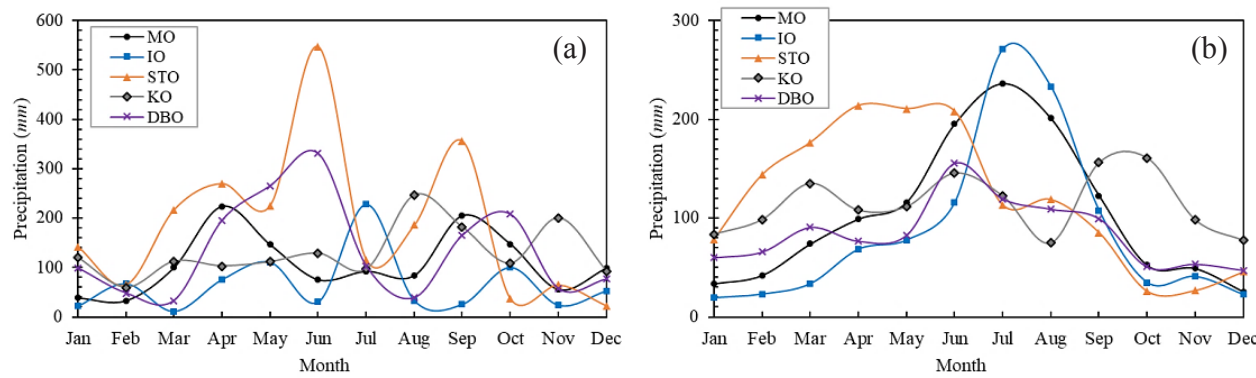

Fig. 5. Variations of average precipitation: (a) Monthly variation throughout the year 2016; (b) Monthly variation over the last 30 years. 
Although it is difficult to find a direct relationship between the wind power density and average precipitation, a comparative closer look at Fig 1(a), Fig 5(a) and Fig 1(b), Fig 5(b) reveals that higher precipitation, in most of the situations, are coinciding with lower average wind speed. A more in-depth study in this regard will definitely help the investors to understand the relationship between the precipitation and wind behaviour at any particular locations.

\subsection{Effect of average humidity}

As mentioned in section 2, due to the unavailability of average humidity data for the last 30 years' duration, the variation of average monthly humidity over the year 2016 is shown only in Fig 6. As humidity is proportional to temperature, the higher temperatures, the more water vapour the air can hold compared to the air at a lower temperature. Humidity is also inversely proportional to air pressure which means the lower the pressure, the higher the humidity. As lower pressure means lesser air molecules, the air can hold more water molecules, thus increasing the humidity. A comparison among Fig 3(a), Fig 4(a) and Fig 6 will help to visualise the above conclusion. Higher humidity decreases wind power density as well. As the humidity increases, the air becomes less dense and gets warmer due to the presence of a greater amount of water molecules in it, thus resulting in lower wind power density. This can be better understood by comparing Fig 6 with Fig 7(a). As noticed, average humidity is generally higher near the middle of the year while wind power density is lower during that period.

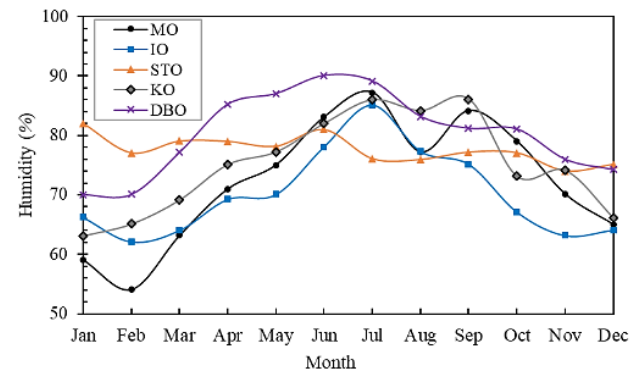

Fig. 6. Variations of average humidity: Monthly variation throughout the year 2016

\subsection{Density of wind power}

Fig 7(a) and Fig 7(b) shows the monthly variations of wind power density and Fig 7(c) shows the annual variations of wind power density.
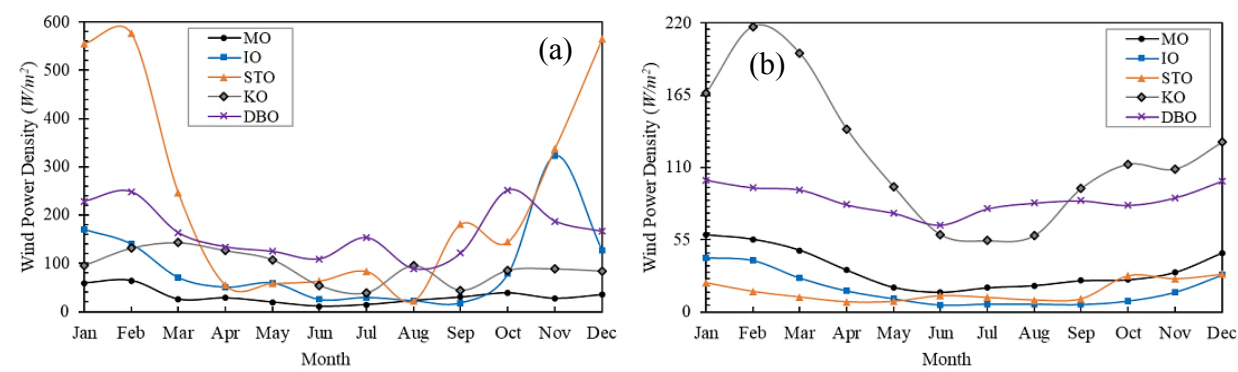


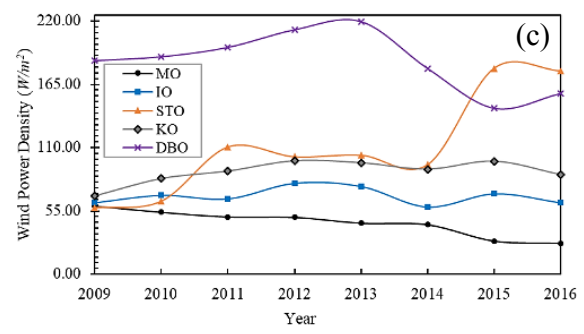

Fig. 7. Wind power density variation: (a) Monthly variation throughout the year 2016; (b) Monthly variation over the last 30 years; (c) Annual variation over 8 years.

Fig 7(b) shows Kamisu Offshore wind farm located at Ibaraki Prefecture had a high wind power density of $217.25 \mathrm{~W} / \mathrm{m} 2$ during February throughout 30 years' period. It had a high wind speed of $7 \mathrm{~m} / \mathrm{s}$, low average temperature of $278.65 \mathrm{~K}$, high air density of 1.267 $\mathrm{kg} / \mathrm{m} 3$, low average precipitation of $98 \mathrm{~mm}$. South-Taipower Offshore wind farm located at Changhua had a high wind power density of $575.68 \mathrm{~W} / \mathrm{m} 2$ during February in the year of 2016. It had a high wind speed of $9.8 \mathrm{~m} / \mathrm{s}$, low average temperature of $291.15 \mathrm{~K}$, high average pressure of $102240 \mathrm{~Pa}$, high air density of $1.223 \mathrm{~kg} / \mathrm{m} 3$, low average precipitation of $60.13 \mathrm{~mm}$ and high average humidity of $77 \%$ in that month.

Fig 7(c) on the other hand, shows that Donghai Bridge Offshore wind farm located at Shanghai had the highest wind power density among the five offshore wind farms throughout the last 8 years. It had the highest average wind speed, second highest average temperature, second lowest air density, second highest average pressure and the highest average humidity over the last 8 years. All these observations highlight the interdependencies of various climate factors and how these complex relationships among the variables affect the density of available wind power in a particular location.

\subsection{Wind directions}

Finally, the wind rose diagrams of the five chosen offshore wind farm are presented in this last subsection. A wind rose diagram is usually generated based on the meteorological observations of wind speed and directions. Wind direction is an important parameter in evaluating the amount of wind energy in an area and it helps the investors to decide the facing of the wind turbines to ensure the maximum efficiency.
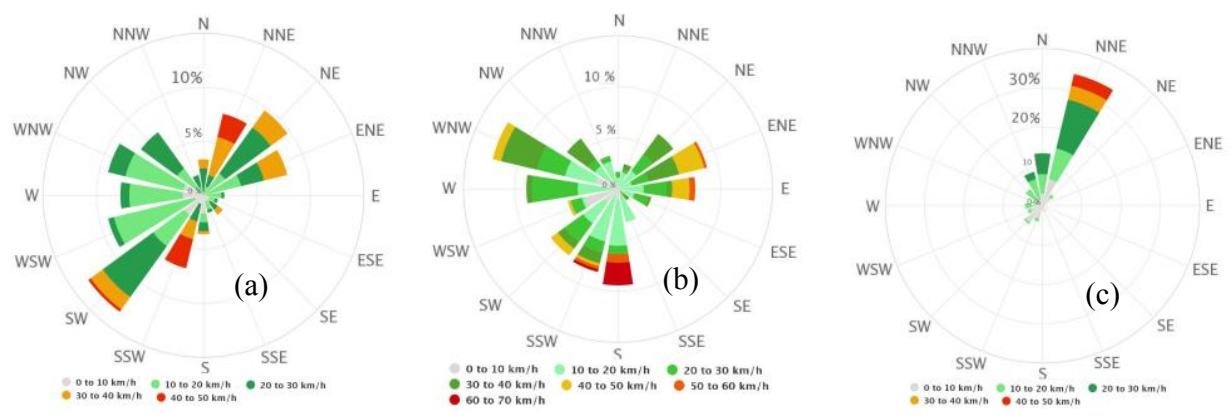

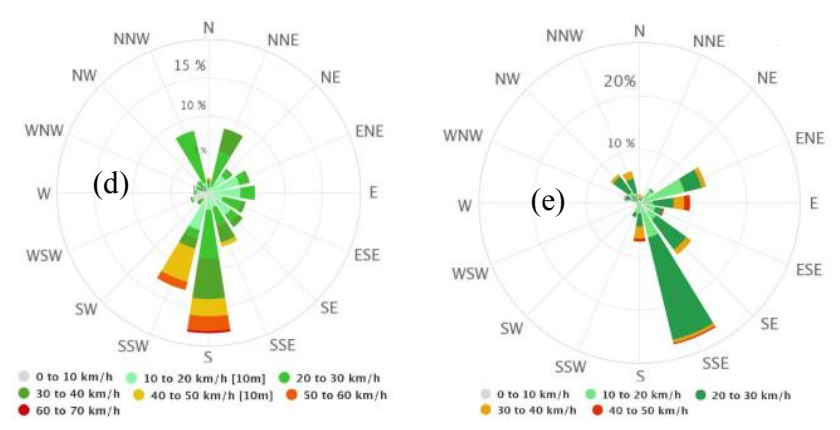

Fig. 8. Wind direction rose diagram: (a) Maritime Offshore; (b) Incheon Offshore; (c) SouthTaipower Offshore; (d) Kamisu Offshore; (e) Donghai Bridge Offshore.

The wind rose diagrams in Fig 8 show the wind directions distribution over a period of two weeks (13 Apr 2018 to 26 Apr 2018) for the five offshore wind farms considered in this study. However, wind rose diagrams with longer durations should be used for practical analysis in order to ensure better accuracy.

\section{Conclusion}

This study highlights both the explicit and implicit dependencies of various climate parameters and their influence on the availability of wind power in an area. Apparently, the average wind speed impacts the most as the wind power is approximately proportional to the cube of wind velocity. However, this usually led to a misconception that high wind speed is certainly better without taking into consideration the specification of the wind turbine. Wind turbines are usually designed for a cut in and cut out speed. Cut in speed is the minimum speed at which the turbine starts operating, which is normally $3-5 \mathrm{~m} / \mathrm{s}$. Cut out speed, on the other hand, is the maximum speed at which the turbine can operate before encountering damage.

Nevertheless, the purpose of this study is to present an approach to analysing the climate parameters at various regions, the reasons for their variations, their interdependencies and how they impact the wind power density. Such background study will let the developers and investors decide on the desired turbine model and dimensions depending on the climate condition of a particular offshore location. It appears that high wind speed, low average temperature, high average pressure, high air density, low average precipitation and low average humidity are usually the optimum conditions for harnessing offshore wind energy. However, further studies are required to be performed to provide a more quantitative and comprehensive conclusion.

A major limitation of this study is that the altitude for the climate parameters is not taken into account, which may affect the accuracy of the findings to some extent. A subsequent study is in progress to improve the efficiency of the energy harvesting using hybrid vertical axis wind turbine (HVAWT). Vertical axis wind turbine (VAWT) is independent of wind direction and requires less space to steer compared to the traditional horizontal axis wind turbine. Besides, solar panel will be added on the surface of VAWT to ensure a consistent power generation in case of intermittent wind speed, thus, providing the hybrid model. 


\section{References}

1. BP (British Petroleum), BP Statistical Review of World Energy, Published Online (2017)

2. A.E. Raftery, A. Zimmer, D.M.W. Frierson, R. Startz, P. Liu, Less than $2{ }^{\circ} \mathrm{C}$ warming by 2100 unlikely, Nature Climate Change, 7, 637 (2017)

3. T. Mauritsen, R. Pincus, Committed warming inferred from observations, Nature Climate Change, 7, 652 (2017)

4. J. Fenger, Impacts of climate change on renewable energy sources, (Norden, Copenhagen, 2007)

5. S.C. Pryor, R.J. Barthelmie, Climate change impacts on wind energy: a review, Renewable and sustainable energy reviews, 14 (1), 430-437 (2010)

6. P. Hou, W. Hu, M. Soltani, Z. Chen, A new approach for offshore wind farm energy yields calculation with mixed hub height wind turbines, IEEE Power and Energy Society General Meeting (PESGM), Boston, MA, 1-15 (2016)

7. C.M.St. Martin, J.K. Lundquist, A. Clifton, G.S. Poulos, S.J. Schreck, Wind turbine power production and annual energy production depend on atmospheric stability and turbulence, Wind Energ. Sci., 1, 221-236 (2016)

8. World Weather Online, Online database. (https://www.worldweatheronline.com/)

9. Meteoblue AG, Online database, Switzerland. (https://www.meteoblue.com/)

10. A. Betz, Introduction to the Theory of Flow Machines, (D. G. Randall, Trans.) Oxford: Pergamon Press (1966) 